\title{
Concomitant caries and calculus formation from in situ dentin
}

\section{caries model [version 1; peer review: 2 approved]}

\section{Frederico B de Sousa1, Pablo J Mangueira1, David R Tames², Sandra S Vianna, Neriede S Santos-Magalhaes ${ }^{4}$}

\author{
${ }^{1}$ Departmento de Morfologia, Centro de Ciências da Saúde, Universidade Federal da Paraíba, Cidade Universitária, 58051-900, João \\ Pessoa, Paraíba, Brazil \\ ${ }^{2}$ Faculdade de Odontologia, Universidade do Vale do Itajaí, Itajaí, 88302-202, Santa Catarina, Brazil \\ ${ }^{3}$ Departamento de Física, Centro de Ciências Exatas e da Natureza, Universidade Federal de Pernambuco, Cidade Universitária, \\ 50670-901, Recife, Pernambuco, Brazil \\ ${ }^{4}$ Laboratório de Imunopatologia Keizo-Asami (LIKA), Centro de Ciências Biológicas, Cidade Universitária, 50670-901, Recife, \\ Pernambuco, Brazil
}

V1 First published: 04 Jan 2013, 2:3

https://doi.org/10.12688/f1000research.2-3.v1

Latest published: 04 Jan 2013, 2:3

https://doi.org/10.12688/f1000research.2-3.v1

\section{Abstract}

The aim of this study was to test the possibility of the concomitant formation of calculus deposits and caries from in situ dentin caries model for short time periods. Six volunteers wore palatal removal appliances with four polished dentin specimens protected from intraoral mechanical forces for up to 14 days. Each volunteer applied a 50\% sucrose solution (four times a day) on the specimens and performed a daily mouthwash with $0.05 \%$ NaF. Samples were removed after 2, 5, 9 and 14 days in situ. Demineralization was analyzed by stereomicroscopy and SEM (secondary electrons and backscattered electrons modes) and calculus was analyzed by energy dispersive spectroscopy and fluorescence spectroscopy. Seventeen samples, at least one sample from each volunteer, presented dental calculus on both carious and non-carious ones, detected in all time intervals. Ca/P ratios of dental calculus ranged from 1.1 to 1.7. Some large calculus deposits on carious surfaces were confirmed by fluorescence. In conclusion, concomitant caries and calculus formation can be found in dentin caries formed in situ. This has important repercussions on the study of surface phenomena on the interface between hard dental tissues and dental plaque.

Keywords

dental caries, dental calculus, caries model, in situ, surface reactions

\section{Open Peer Review}

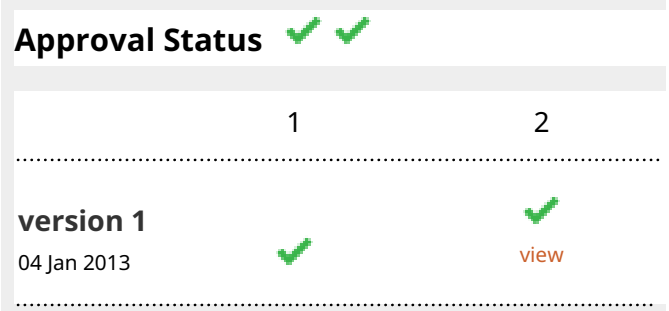

1. Leonard A. Crocombe, The University of Adelaide, Adelaide, Australia

2. Neville Gully, The University of Adelaide, Adelaide, Australia

Any reports and responses or comments on the article can be found at the end of the article. 
Corresponding author: Frederico B de Sousa (Fredericosousa@hotmail.com)

Competing interests: No competing interests were disclosed.

Grant information: The first author thanks the Brazilian Ministry of Education (CAPES) for financial support (doctorate scholarship). The other authors are grateful to CNPq Brazilian Federal Agency of Research.

The funders had no role in study design, data collection and analysis, decision to publish, or preparation of the manuscript.

Copyright: @ 2013 de Sousa FB et al. This is an open access article distributed under the terms of the Creative Commons Attribution License, which permits unrestricted use, distribution, and reproduction in any medium, provided the original work is properly cited. Data associated with the article are available under the terms of the Creative Commons Zero "No rights reserved" data waiver (CC0 1.0 Public domain dedication).

How to cite this article: de Sousa FB, Mangueira PJ, Tames DR et al. Concomitant caries and calculus formation from in situ dentin caries model [version 1; peer review: 2 approved] F1000Research 2013, 2:3 https://doi.org/10.12688/f1000research.2-3.v1

First published: 04 Jan 2013, 2:3 https://doi.org/10.12688/f1000research.2-3.v1 


\section{Introduction}

In situ caries models are not expected to give rise to calculus formation. However, the formation of loosely mineralized deposits in dental plaque concomitantly with carious dissolution of enamel, in an environment with fluoridated mineralizing solution, has been reported $^{1}$. In a morphological study with transmission electron microscopy, those deposits were shown not to be identical to calculus as they were never present within intact bacterial cells ${ }^{2}$. In addition, it was shown by scanning electron microscopy (SEM) that calculus (firmly bound to hard dental tissue) could develop on dentin specimens subjected to an in situ carious attack with a daily application of a $50 \%$ sucrose solution in individuals living in a water-fluoridated area for periods of four weeks ${ }^{3}$. While demineralization is likely in such models, no clear-cut evidence was presented. In this study, some samples with calculus had the cariogenic challenge disturbed by weekly mechanical plaque removal, raising the hypothesis that the concomitant development of caries and calculus may occur during shorter periods under the given conditions.

The aim of this study is to report concomitant formation of calculus deposits and caries on dentin surfaces submitted to an in situ caries model (using sucrose and fluoride) for short time periods (2-14 days).

\section{Material and methods}

\section{Experimental design}

Human dentin specimens $(3 \times 3 \mathrm{~mm})$ from non-erupted third molars, previously autoclavated, had their surfaces consecutively polished with slurries of decreasing grain size until the alumina was $1 \mathrm{~mm}$. Then, they were mounted in customized hand-made resinous removable palatal appliances (thin resinous removable plates placed on the hard palate only and extending from the area close to the central incisors to area close to the first molars), each one containing four specimens distributed in two pairs each in a different side of the appliance, where they were protected from intra-oral mechanical forces by means of plastic perforated tape. A space of up to $2 \mathrm{~mm}$ was left between the specimen and the tape. In the mouth, specimens were located near the palatal surfaces of the first permanent molar and the first premolar.

Six volunteers, aged 20-29 years, were selected on the basis of the following criteria: (i) to be otherwise healthy (no medication regimen), (ii) no calculus treatment in the last two years and no clinical calculus deposits at the time of the study, and (iii) to present normal stimulated salivary flow. All volunteers were dental students who lived in non water-fluoridated areas, and were given fluoridated dentifrices (1500 ppm of the same brand) daily. All volunteers provided signed informed consent. Ethical approval was obtained from the Universidade do Vale do Itajaí Human Research Ethics Committee.

Intra-oral periods lasted fourteen days and the volunteers were instructed to use the appliances all day long, except during meals. Two drops of a 50\% sucrose solution (the same applied previously) ${ }^{3}$ was applied onto the specimens only, four times a day to mimic meals, and a $0.05 \% \mathrm{NaF}$ solution was provided to perform one daily mouthwash for about one minute with the appliance in the mouth (at a different time to the sucrose rinsing). Instructions were given to replace the appliance in the mouth just after the sucrose rinsing and to not brush on the specimens. For each volunteer, specimens were removed after 2, 5, 9 and 14 days of intra-oral period. Six other polished specimens prepared in the same way described above, not exposed to the oral cavity, were also selected for reproducibility during morphological analysis, to make a total of 30 specimens. After the in situ period, specimens were stored in $0.1 \%$ timol prior to further analysis.

\section{Scanning electron microscopy (SEM) and} energy-dispersive spectroscopy (EDS)

All samples were treated with $\mathrm{NaOCl} 5 \%$ for 15 minutes, to remove organic coatings, then critical point dried with $\mathrm{CO}_{2}$-atmosphere of $10^{-2}$ Torr- and coated with a $10 \mathrm{~nm}$-thick layer of gold. The secondary electron detector of a scanning electron microscope JEOL 5900HV (voltage of $15 \mathrm{KeV}$ ) was used. Each specimen was analyzed under tilting angles of $0^{\circ}$ and $40^{\circ}$. EDS analyses were performed in representative areas by a VOYAGER system attached to the microscope using the following parameters: spatial resolution of $1 \mathrm{~mm}$, electron beam area of $10 \mathrm{~mm}$, working distance of $8-9 \mathrm{~mm}$, voltage of 15 $\mathrm{KeV}$ and a live time of $60 \mathrm{~s}$. Ca/P (mol/mol) ratios (mean of 5 measurements) were analyzed using a standardless method-intensity of the standard calculated on the basis of the spectral properties of the sample ${ }^{4}$-with corrections for atomic number, absorption and fluorescence (ZAF correction). SEM analysis of surface changes (demineralization and dental calculus) was performed twice by blinded examiners with a time interval of seven days between the two analyses. A set of 3 images from each sample was chosen. The Kappa test was used to calculate agreement. Only Schroeder's type A dental calculus mineralization centers (with mineralized bacterial bodies outlines $)^{5}$ were considered.

\section{Stereomicroscopy}

After SEM, all samples were treated with $\mathrm{NaOCl} 5 \%$ for 15 minutes to remove the gold coating and then hemi-sectioned centrally on the exposed surface. The surfaces created after cutting were gently polished with alumina $10 \mathrm{~mm}$ and then analyzed under the stereomicroscope (Leica MZ12, Leica, Switzerland). Image analysis for the automated identification of demineralized areas and lesion depth measurements were performed using Leica QWIN Plus software (Leica, Switzerland). A standard margin of color discrepancy detection in the software was used for all samples when the software was asked to differentiate sound and carious dentin. The only influence of the operator was to choose a $1 \mathrm{~mm}$-wide central area for automated lesion depth measurement.

\section{Fluorescence spectroscopy and backscattered scanning electron microscopy (BSE-SEM)}

In samples that presented thick (> $100 \mathrm{~mm}$ in height) and extensive calcified deposits, a scalpel was used to remove the surface by scraping after stereomicroscopy. The scraped material was dissolved in a solution of $\mathrm{HCl} 27 \%(\sim 0.2 \mathrm{ml})$, dispensed in a quartz cuvette and submitted to fluorescence spectroscopy in a commercial photon-counting spectrofluorometer (PC1, ISI, USA and Vinci software, ISI, USA) equipped with a xenon arc lamp operating at $10 \mathrm{~mA}$, using $1 \mathrm{~mm}$ slits (bandwidth of $8 \mathrm{~nm}$ ). Excitation wavelength $\left(\lambda_{\text {excit }}\right)$ was $416 \mathrm{~nm}$ and the emission $\left(\lambda_{\text {emis }}\right)$ was collected from 425 to $800 \mathrm{~nm}$ (mean of 15 readings). Fluorescence of the other two saturated solutions in $\mathrm{HCl} 27 \%$, one with human dental calculus and another with human dentin, were also analyzed. 
Next, all samples had their cut surface prepared (polished, dried and metallic coated as described above) for SEM analysis using a backscattered electron detector (voltage of $15 \mathrm{KeV}$ ) in order to confirm the presence of demineralization. During this latter procedure, the demineralized layer of most samples broke apart so that only the inner parts remained for BSE-SEM analysis.

\section{Statistical analysis}

The differences between in situ periods of all volunteers with regard to lesion depth were evaluated by paired $t$ test (significance limit at $5 \%$ ).

\section{Results and discussion}

The occurrence of demineralization and calcified deposits was depicted from SEM examination (Table 1). Kappa's coefficients of intra-examiner agreement were 0.88 and 0.83 , and 0.78 for interexaminer agreement of the diagnosis of demineralization with SEM. For dental calculus, it was decided to count only cases with full agreement between examiners. Mean lesion depth values were 0.0, 0.197 $( \pm 0.059), 0.442( \pm 0.062)$ and $1.100 \mathrm{~mm}( \pm 0.212)$ for $2,5,9$ and 14 in situ periods, respectively (differences were statistically significant, $\mathrm{p}<0.05)$. BSE-SEM analysis confirmed the presence of demineralization (lower gray levels due to lower mean atomic number) detected by stereomicroscopy.

Seventeen samples presented calculus deposits (14 with demineralization; Table 1). Seven of these presented $\sim 50 \%$ or more of the surface area covered by the deposits. In the other samples, deposits formed isolated or connected islands of $50-500 \mathrm{~mm}$ wide. $\mathrm{Ca} / \mathrm{P}$ ratios resemble the structures of dicalcium phosphate $(\mathrm{Ca} / \mathrm{P}$ of 1.0$)$, octacalcium phosphate $(\mathrm{Ca} / \mathrm{P}$ of 1.3$)$, magnesium whitlockite $(\mathrm{Ca} / \mathrm{P}$ of 1.5) and hydroxyapatite ( $\mathrm{Ca} / \mathrm{P}$ of $1.67-2.3)^{5-7}$ (Table 1$)$. Mean $\mathrm{Ca} / \mathrm{P}$ ratio of dentin (for all samples) was $1.88 \mathrm{~mol} / \mathrm{mol}( \pm 0.22)$, compatible with hydroxyapatite. Demineralization surrounding calculus deposits occurred in thirteen samples.

Table 1. Occurrence of demineralization and calculus deposits (with mean of $\mathbf{5 ~ C a / P}$ ratios obtained by EDS-SEM). * Samples with $50 \%$ or more of their surfaces covered by calculus.

\begin{tabular}{|c|c|c|}
\hline Volunteer & Demineralization & $\begin{array}{l}\text { Dental calculus }(\mathrm{Ca} / \mathrm{P} \text {, } \\
\mathrm{mol} / \mathrm{mol})\end{array}$ \\
\hline I & 5,9 and 14 days & 5 days $(1.04 \pm 0.03)$ \\
\hline$\|$ & $2,5,9$ and 14 days & $\begin{array}{l}2(1.12 \pm 0.04), 9(1.40 \pm \\
0.02) \text { and } 14^{*} \text { days }(1.53 \pm \\
0.04)\end{array}$ \\
\hline III & 5,9 and 14 days & $\begin{array}{l}2(1.49 \pm 0.07), 5(1.48 \pm \\
0.05) \text { and } 9^{*} \text { days }(1.43 \pm \\
0.06)\end{array}$ \\
\hline IV & 5,9 and 14 days & $\begin{array}{l}2(1.47 \pm 0.02), 5^{\star}(1.52 \pm \\
0.04), 9^{*}(1.66 \pm 0.06) \text { and } \\
14 \text { days }(1.73 \pm 0.05)\end{array}$ \\
\hline V & 5, 9 and 14 days & $\begin{array}{l}2(1.38 \pm 0.02), 5(1.51 \pm \\
0.05), 9^{*}(1.54 \pm 0.05) \text { and } \\
14^{*}(1.71 \pm 0.06) \text { days }\end{array}$ \\
\hline VI & $2,5,9$ and 14 days & $\begin{array}{l}5(1.56 \pm 0.05) \text { and } 14^{*}(1.41 \\
\pm 0.04) \text { days }\end{array}$ \\
\hline
\end{tabular}

The crystalline structure of young calculus is reported to be mainly of dicalcium phosphate in the early stages, after which octacalcium phosphate develops and, with further growth, whitlockite and hydroxyapatite are formed ${ }^{5}$. The driving force for the mineralization of dental plaque is the supersaturation of plaque fluid with respect to calcium phosphate, which is $\mathrm{pH}$ - and temperature-dependent. It is known that dicalcium phosphate and octalcacium phosphate can be precipitated in acidic environments whereas hydroxyapatite is dissolved ${ }^{7,8}$. Magnesium whitlockite or simply whitlockite (a type of calcium phosphate where calcium is partly substituted by magnesium) has a structure that is not easily distinguished from $\beta$-tricalcium phosphate or magnesium-containing $\beta$-tricalcium phosphate, and this is the reason why they have been referred as synonyms. However, it is known that they are distinguishable by careful powder diffractometry ${ }^{10}$, although both present a $\mathrm{Ca} / \mathrm{P}$ ratio of $1.5^{7}$. While $\beta$-tricalcium phosphate does not form in biological systems, whitlockite is found in many biological mineralizations? . Whitlockite precipitates at low, neutral or high $\mathrm{pH}$, with magnesium stimulating whitlockite precipitation at the expense of hydroxyapatite $^{7}$. The presence of hydroxyapatite most probably reflects $\mathrm{pH}$ fluctuations (with either neutral or high $\mathrm{pH}$ events) during the periods of time employed. In this context, it is possible to chemically explain the concomitant calculus and caries formation in our model.

Crystallite morphology and $\mathrm{Ca} / \mathrm{P}$ ratios resembling hydroxyapatite in 10-day old calculus deposits have been reported previously ${ }^{11}$.

As the in situ period proceeded, calculus deposits (resembling the morphology of Schroeder's type A calculus deposits ${ }^{5}$ ) with increased height, macroscopic in some cases, were seen on demineralized areas (Figure 1A-C). The shapes of intact bacterial bodies (cocci, filaments and rods) remained within extracellular calcified trabeculae, indicating that the mineralization process was preferably extracellular. Some deposits were identified only after tilting the sample to $40^{\circ}$. No bacterial cell remnants were identified within calculus deposits.

Three samples (from two volunteers; in situ times of 9 and 14 days) that presented "large" deposits of calculus and caries were submitted to fluorescence spectroscopy. All of them presented fluorescence of dental calculus (Figure 1F: the same sample of Figure. 1A-E) and histological demineralization (Figure 1C-E). The dark layer shown in Figure 1E represents demineralization (preserved part after polishing) seen under BSE-SEM.

Fluorescence of human dental calculus in acid solution has been shown to present the highest emission with $\lambda_{\text {excit }}$ at $416 \mathrm{~nm}$ and $\lambda_{\text {emis }}$ peaks at 620 and $660 \mathrm{~nm}$ (originated from hematoporphyrin) ${ }^{12}$. A lower fluorescence emission band below $580 \mathrm{~nm}$ has also been reported for human dental calculus ${ }^{13}$. Human dentin fluoresces with a $\lambda_{\text {emis }}$ peak at $440 \mathrm{~nm}$ and does not present any emissions in the region of 580-700 nm ${ }^{14}$, which is in accordance with our fluorescence data for $\lambda_{\text {excit }}$ at $416 \mathrm{~nm}$ (Figure 1F). The selected samples with "large" calcified deposits (deposits $<100 \mu \mathrm{m}$ in height cannot be detected by a spectrofluorometer system with a lamp source as excitation light ${ }^{15}$ ) showed a mixture of fluorescence bands of human dental calculus and human dentin (Figure 1F). The double treatment with $\mathrm{NaOCl} 5 \%$ and the absence of bacterial cell 

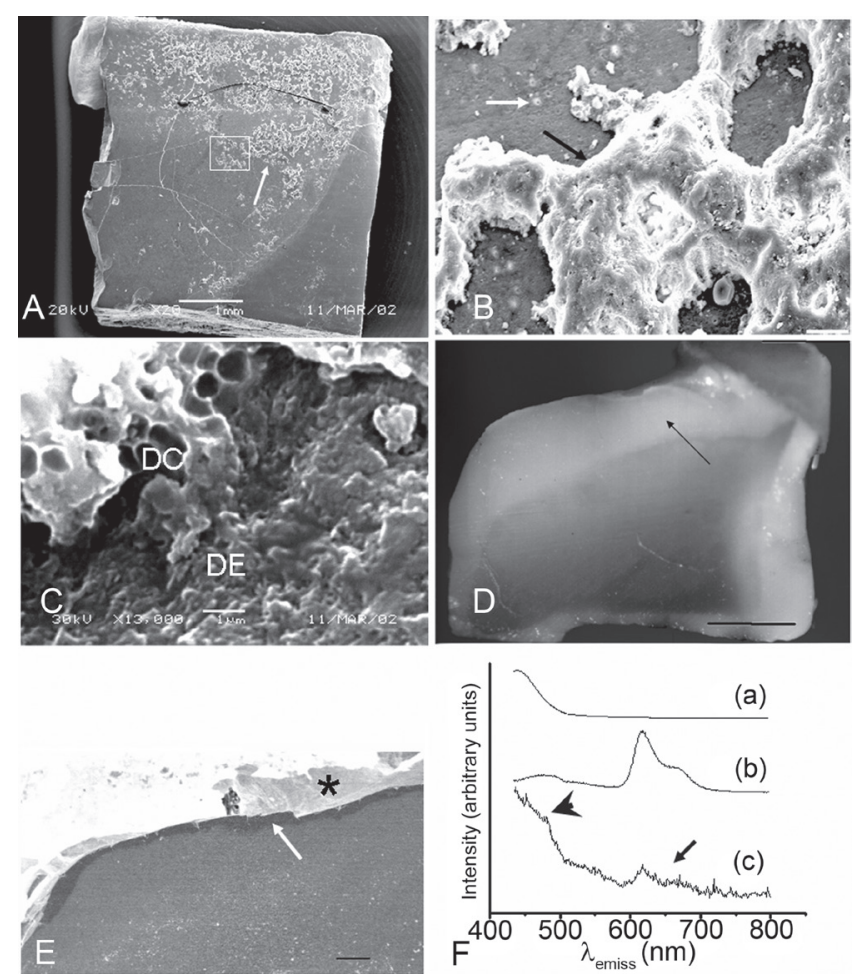

Figure 1. A, calculus deposits (arrow), of macroscopic size, on a 9-day sample with demineralization (Bar = $1 \mathrm{~mm})$. B, detail of the area outlined in "A", showing opening of dentinal tubules (white arrow) and dental calculus (black arrow) (Bar = $20 \mathrm{~mm}$ ). C , detail of the area close to the white arrow in "B", showing mineralized bacterial outlines delimitating spaces of $\sim 1 \mathrm{~mm}$ in diameter (DC, dental calculus) and the demineralized dentin $(\mathrm{DE})($ Bar $=1 \mathrm{~mm})$. $\mathbf{D}$, histological aspect of the same sample after hemi-sectioning showing demineralization (black arrow) below the experimental surface $(B a r=1 \mathrm{~mm})$. Opaque outline is demineralization caused by bacterial acid infiltrated around the sample. E, BSE-SEM image (bar $=300 \mathrm{~mm}$ ) showing, below the fractured surface (asterisk), a dark layer (white arrow) representing the preserved part of the demineralised area indicated by the black arrow in "D". F, fluorescence spectroscopy data of different samples dissolved in $\mathrm{HCl} 27 \%$ and excited with light at $416 \mathrm{~nm}$ : (a), human dentin; (b), human dental calculus; and (c), sample from the surface of the sample shown in "A", showing fluorescence of dentin (arrowhead) and dental calculus (arrow).

remnants during SEM examination exclude the influence of loosely bound organic material of bacteria on the observed fluorescence.

The concomitant development (based on our time intervals) of caries lesions and calculus deposits using an in situ caries model reported here occurred under conditions known to cause the formation and growth of dental plaque. Combining SEM, fluorescence spectroscopy and stereomicroscopy (Figure 1A-F), we have shown caries and calculus developments in the same dentin sample that was originally non-carious and had not been exposed to the oral cavity before the in situ experiment. Our model was able to promote time-dependent demineralisation (seen from lesion depth data), which means that volunteers followed instructions properly. To our knowledge, this is the first time that this phenomenon has been reported on the basis of the combination of such mutually validating techniques.

\section{Conclusion}

In conclusion, calculus formation in active cariogenic dental plaque has important repercussions on the study of surface phenomena on the interface between hard dental tissues and dental plaque. It is also important in the development and the evaluation of anti-tartar and caries-preventative agents. Our study shows that more attention should be paid by those studying in situ dentin caries to the identification of calculus on hard dental tissues exposed to in situ caries models.

\section{Author contributions}

Sousa FB and Tames DR designed the study and the intra-oral appliances. Mangueira PJ selected volunteers, prepared intra-oral appliances, and dentin samples. Sousa FB and Mangueira PJ conducted the in situ protocols and followed up with volunteers. Sousa FB, Vianna SS and Santos-Magalhaes NS conducted the fluorescence spectroscopy, SEM and BSE analysis, and statistical analysis. Sousa FB and Tames DR wrote the paper. All authors read and approved the final manuscript.

\section{Competing interests}

No competing interests were disclosed.

\section{Grant information}

The first author thanks the Brazilian Ministry of Education (CAPES) for financial support (doctorate scholarship). The 
other authors are grateful to CNPq Brazilian Federal Agency of Research.

The funders had no role in study design, data collection and analysis, decision to publish, or preparation of the manuscript.

\section{Consent}

All volunteers who used the intra-oral appliances signed a written informed consent before participating in this study. No payment was provided to volunteers in return for their participation in this study.
1. Pearce El: Effect of plaque mineralization on experimental dental caries. Caries Res. 1982; 16(6): 460-471. PubMed Abstract

2. Pearce El, Wakefield JS, Sissons $\mathrm{CH}$ : Therapeutic mineral enrichment of dental plaque visualized by transmission electron microscopy. J Dent Res. 1991; 70(2): 90-94. PubMed Abstract | Publisher Full Text

3. Sousa FB: The effect of weekly mechanical plaque removal on the in situ development of dentin caries (in Portuguese). Master dissertation. Universidade Federal de Santa Catarina, Florianópolis, SC, Brazil 1996.

4. Goldstein JI, Newbury DE, Echlin P, et al.: Scanning electron microscopy and x-ray microanalysis. 2. ed, Plenum, New York 1992. Reference Source

5. Schroeder HE: Formation and inhibition of dental calculus. J Periodontol. 1969; 40(11): 643-6.

PubMed Abstract | Publisher Full Text

6. Kodaka $T$, Ohohara $Y$, Debari K: Scanning electron microscopy and energydispersive $x$-ray microanalysis studies of early dental calculus on resin plates exposed to human oral cavities. Scanning Microsc. 1992; 6(2): 475-485. PubMed Abstract

7. Legeros RZ: Calcium Phosphates in Oral Biology and Medicine. Monogr Oral Sci. 1991; 15: 1-201. PubMed Abstract

8. Johnsson MS, Nancollas GH: The Role of Brushite and Octacalcium Phosphate in Apatite Formation. Crit Rev Oral Biol Med. 1992; 3(1-2): 61-82.

PubMed Abstract
9. Mathew M, Takagi S: Structure of biological minerals in dental research. J Res Natl Inst Stand Technol. 2001; 106: 1035-1044. Reference Source

10. Gopal R, Calvo C: Strucure relationship of whitlockite and $\beta-\mathrm{Ca}_{3}\left(\mathrm{PO}_{4}\right)_{2}$. Nature Phys Sci. 1972; 237: 30-32.

Reference Source

11. Kodaka $T$, Ohohara $Y$, Debari K: Scanning electron microscopy and energydispersive x-ray microanalysis studies of early dental calculus on resin plates exposed to human oral cavities. Scanning Microsc. 1992; 6(2): 475-485. PubMed Abstract

12. Reis MM, Biloti DN, Ferreira MM, et al.: PARAFAC for spectral curve resolution: a case study using total luminescence in human dental tartar. Appl Spectrosc. 2001; 55: 847-851. Reference Source

13. Dolowy WC, Brandes ML, Gouterman M, et al.: Fluorescence of dental calculus from cats, dogs, and humans and of bacteria cultured from dental calculus. $J$ Vet Dent. 1995; 12(3): 105-109. PubMed Abstract

14. Matsumoto H, Kitamura S, Araki T: Autofluorescnce in human dentine in relation to age, tooth type and temperature measured by nanosecond time-resolved fluorescence microscopy. Arch Oral Biol. 1999; 44(4): 309-318. PubMed Abstract

15. Lakowicz JR: Principles of fluorescence spectroscopy. 2nd ed, Kluwer Academic/Plenum, New York 1999; 725. Reference Source 


\section{Open Peer Review}

\section{Current Peer Review Status:}

\section{Version 1}

Reviewer Report 23 April 2013

https://doi.org/10.5256/f1000research.310.r906

(C) 2013 Gully N. This is an open access peer review report distributed under the terms of the Creative Commons Attribution License, which permits unrestricted use, distribution, and reproduction in any medium, provided the original work is properly cited.

\section{Neville Gully}

School of Dentistry, The University of Adelaide, Adelaide, Australia

It was noted that all dentin samples were exposed to sucrose solutions, fluoride and were protected by tape. Only the unexposed slabs were used as controls and none of these three conditions were controlled. A more complete picture would have been possible with their inclusion.

The authors claimed "It is known that dicalcium phosphate and octacalcium phosphate can be precipitated in acidic environments whereas hydroxyapatite is dissolved." They listed references 7 and 8 to support this statement. However, I was unable to access reference 7 and could not find supporting data in reference 8 . While DCP is slightly less soluble than HAP around pH4 I would not consider that to mean that either DCP or OCP readily precipitate at that $\mathrm{pH}$.

Competing Interests: No competing interests were disclosed.

\section{I confirm that I have read this submission and believe that I have an appropriate level of expertise to confirm that it is of an acceptable scientific standard.}

Author Response 20 May 2013

Frederico Sousa, Centro de Ciências da Saúde, Universidade Federal da Paraíba, Cidade Universitária, 58051-900, João Pessoa, Paraíba, Brazil

I thank the reviewer for his valuable comments and his opinion to accept the article is greatly acknowledged by us.

Regarding the first paragraph of the reviewer's comment, we understood that the critique was that some control was lacking. We think that the inclusion of samples that were exposed to the oral environment but did not develop caries would no add relevant information for the aim of the study. The in situ caries induction aimed at producing caries 
lesions with known history and with severity directly proportional to the in situ time. Mean lesion depth increased with in situ time, confirming the prediction. In an environment where caries develops, surface features of the samples were analyzed in order to verify whether calculus deposits could have been formed under the same conditions. Such conditions are those common to in situ caries models. Because the length of the article is short, we focused on the more relevant data (samples with dental calculus). If we had exposed dentin samples that remained sound after the in situ period, the presence of absence of calculus deposits on those samples would have not contributed to prove that calculus deposits can be formed concomitantly with caries lesions in short time intervals in an in situ caries model.

In the case of precipitation of dicalcium phosphate (DCP) and octacalcium phosphate (OCP) in acidic environments, Johnsson et al. 1992 describes evidence indicating that formation of both DCP and OCP in vivo, during normal mineralization, is quite different from the conditions operating under pathological mineralization. The authors cite reports of the precipitation of DCP and OCP in slightly acidic conditions (please see last paragraph of the second column on page 78 of Johnsson et al. 1992). The critical pH of dentin is between 6.5 and 7 (Hoppenbrouwers et al. 1987). There is a pH range below the critical pH of dentin that can be considered as slightly acidic, and so it is consistent with the possible precipitation of both DCP and OCP in our samples. Regarding formation of DCP and OCP in acidic conditions in vitro, evidence can be found in the following papers; De Rooij et al. 1984 and Lundager Madsen et al. 1991.

Competing Interests: This comment was posted by the authors of the study.

Reviewer Report 21 January 2013

https://doi.org/10.5256/f1000research.310.r715

(c) 2013 Crocombe L. This is an open access peer review report distributed under the terms of the Creative Commons Attribution License, which permits unrestricted use, distribution, and reproduction in any medium, provided the original work is properly cited.

\section{Leonard A. Crocombe}

Australian Research Centre for Population Oral Health and the School of Dentistry, The University of Adelaide, Adelaide, Australia

Competing Interests: No competing interests were disclosed.

I confirm that I have read this submission and believe that I have an appropriate level of expertise to confirm that it is of an acceptable scientific standard. 
The benefits of publishing with F1000Research:

- Your article is published within days, with no editorial bias

- You can publish traditional articles, null/negative results, case reports, data notes and more

- The peer review process is transparent and collaborative

- Your article is indexed in PubMed after passing peer review

- Dedicated customer support at every stage

For pre-submission enquiries, contact research@f1000.com 